\title{
THE ARAB IMAGE FOUNDATION: COLLECTING, STUDYING AND PRESERVING PHOTOGRAPHS FROM THE MIDDLE EAST AND NORTH AFRICA
}

\author{
Zeina Arida, Rima Mokaiesh \\ Arab Image Foundation, Beirut, Lebanon \\ zeina.arida@fai.org.lb, rima.mokaiesh@fai.org.lb
}

KEYWORDS: Arab Image Foundation, Arab world, Chadirji, modern cultural heritage, Madani, Middle East, networks, photography, preservation, training, Zaatari

\begin{abstract}
:
The Arab Image Foundation (AIF) has been collecting, studying and preserving photographs from the Middle East and North Africa since 1997. It runs curatorial and research projects, and activities related to photograph preservation. Fifteen years after its creation, the AIF's archive holds over 600,000 images, including complete collections entrusted by photographers such as Hashem el Madani (Lebanon) or Kamil and Rifaat Chadirji (Iraq). Such collections require sustained efforts in terms of archiving, documenting and digitizing. In addition to the care of its own collection, the AIF's current preservation programs include the Middle East Photograph Preservation Initiative (MEPPI), which seeks to identify and offer training to significant photographic collections in a region where expertise in conservation and preservation is all too often absent. The AIF is also a member of the Modern Heritage Observatory, a coalition which campaigns for the preservation of modern cultural heritage through the creation of a regional network of individuals and institutions committed to its cause.
\end{abstract}

\section{COLLECTING PHOTOGRAPHS}

Established in Beirut in 1997 by a group of prominent Arab photographers, video artists and curators, the Arab Image Foundation is a non-profit organization dedicated to the collection, study and preservation of photography and other related visual material from the Middle East, North Africa, and the Arab diaspora.

Fifteen years after its creation, the Arab Image Foundation's archive today holds over 600,000 photographs. Over the years, AIF members have gathered photographic material from a diverse range of sources: from families to professional studios, and photographers to collectors.

The Arab Image Foundation works to make its collection accessible to the public through a wide spectrum of activities, including site-specific exhibitions, publications, videos and an online image database. It seeks to encourage critical approaches to the reading and interpretation of photographs.

The contents of the AIF collection represent both the foundation's central preservation mandate and the specific research interests of its members. The artists, writers, filmmakers and historians affiliated with the AIF have, to date, initiated research projects in Lebanon, Syria, Palestine, Jordan, Egypt, Morocco, Iraq, Iran, Mexico, Argentina and Senegal. The result is a dynamic and at times idiosyncratic collection that not merely illustrates the history of photography in the region but rather situates a wealth of different photographic practices within a complex context of social, economic, political and cultural factors.

Authored by professionals, amateurs and anonymous photographers alike, the collection's images cover a wide breadth of genres and styles - including documentary, historical, reportage, industrial and advertising photography. The diverse range of subjects includes architecture, family and studio portraits, fine art, landscapes, still life and nudes.

In addition to expanding the AIF's collection, the research projects make valuable contributions to the study of photography in the region by collecting information on photographers: their biographies and the conditions informing their practice. Inevitably, the research projects raise questions about how images are used, and their relationship to notions such as identity, history and memory. The AIF's approach to assembling a collection differs from that of more traditional historians, conservators or curators in that the process is primarily led by the critical and creative work of artists.

Through the efforts of the AIF, the photographic works of Van Leo (Egypt), Latif el Ani (Iraq) and Hashem el Madani (Lebanon) have been introduced to an international audience. Prints and negatives from these and other collections selected for their artistic and historical value are scanned in high resolution and made accessible via the AIF's internal database, with approximately 20,000 of these images also available online on www.fai.org.lb. The standards used for the digitization and e-preservation of the AIF archive have been developed by the AIF in the course of the last 15 years. Several consultants helped develop the AIF's digitization guidelines. In particular, Franziska Frey, today Head of Preservation and Digital Imaging Services at the Harvard Library, reviewed and edited the guidelines in 2011. The photos are documented in the AIF database with extensive metadata available.

Since its inception, the AIF has produced fifteen exhibitions and seven publications in partnership with international museums, galleries and cultural institutions. The collection has also proved an invaluable resource for artists' projects, curatorial initiatives and academic research. Its premises are open to the public daily and include a unique library dedicated to photography and extensive research facilities.

\section{STUDYING PHOTOGRAPHS}

\subsection{The Madani collection}

One of the AIF's long-term areas of study is the Madani Project, featuring the work of studio photographer Hashem el Madani (1928-). The entire archive of Madani's Studio Shehrazade is taken as study material to understand the complex relationship tying a studio photographer to his working space, 
his equipment and tools, economy, and aesthetics, and further explores his ties to his clients, society, and the city in general.

Initiated by artist Akram Zaatari and the Arab Image Foundation, the project reflects, on the one hand, Zaatari's interest in living situations and configurations as objects of study that bear witness to modern traditions and complex social relationships, and, on the other, the AIF's commitment to preserving, indexing and studying photographic collections from the Arab world. The Madani Project comprises a series of thematic exhibitions, publications, and videos centered on the photographer and his work.

Through this project, the Studio Shehrazade archive is gradually being identified, detailed, and preserved by the AIF, and, with over 100,000 negatives, is one of the AIF's largest collections.

Hashem el Madani was born in Saida, but of Saudi Arabian descent. In 1947, Madani travelled to Palestine seeking employment, and began working in Haifa as an assistant to a Jewish immigrant photographer named Katz. He returned to Saida a year later at the outbreak of the events of 1948. In Saida, Madani bought his first $35 \mathrm{~mm}$ camera for 200 Lira, and began to work as an itinerant photographer. He would walk in the city offering his services to shop owners and passers-by. At the same time, he transformed a space in his parents' home into a studio. By 1952 Madani had raised enough money to buy new equipment and rent a studio of his own in the same building as Cinema Shehrazade in Riad El Solh street, thereby giving the studio its name.

Madani's archive sheds light on the life of a city during half a century of dramatic sociopolitical change. However, the studio was most active over the course of the 1950s, photographing residents of Saida - families, individuals, shop owners and workers - and as such providing a portrait of the city from this important historical period.

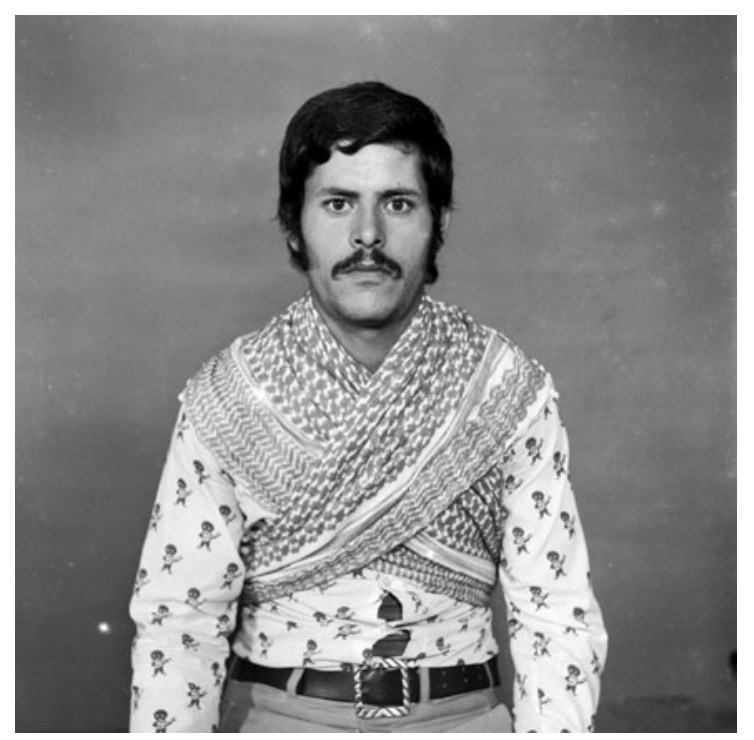

Syrian resistant

Saida, Lebanon, 1970s

Hashem el Madani, Studio Shehrazade

Copyright (C) Arab Image Foundation

From 2004 to 2007, the AIF, with the support of the Prince Claus Fund, was able to process and archive over 100,000 negatives, and digitize a selection of 30,000 . Following this effort, a 2010 grant from Bank America's Art Conservation Project allowed the AIF to preserve and digitize further the collection. A portion of the digitized images is available on the AIF website, at www.fai.org.lb.

Hashem el Madani's archive is the AIF's longest running research project to date. So far, work on Madani's archive has produced two books, three exhibitions and two videos. One exhibition in particular, titled "Itinerary", is a permanent installation dating back to 2007, when the AIF installed 60 photographs in shops scattered throughout the old city of Saida. These portraits by Madani of shop owners standing next to their stores were each exhibited in the exact locations of the original stores - of which some are still standing, and of which others have taken on very different forms. This interactive installation encourages the public to engage with the new shop owners and, if curious, to discover Saida through its oral history.

\subsection{The Chadirji collection}

The Chadirji collection is one of the most recent additions to the AIF archive. It was entrusted to the AIF by Rifaat Chadirji, a renowned Iraqi architect and photographer and comprises his own archive, as well as that of his father, Kamil Chadirji. The latter was a journalist, political activist, and an avid photographer who documented social change and injustices through his lens. He sought to record the disappearing traditional Iraq and to document the poverty that existed therein. K. Chadirji's collection of 1,200 images had already been through a rigorous process of archiving before arriving at the Arab Image Foundation in the spring of 2012. The collection, which spans his work in various countries including Iraq, Lebanon, Syria and Iran, is dated chronologically and classified according to subject matter. It features images of prominent personalities in Iraqi society, intellectual gatherings and social life in addition to self-portraits, from the early 1920 s to the 1960s.

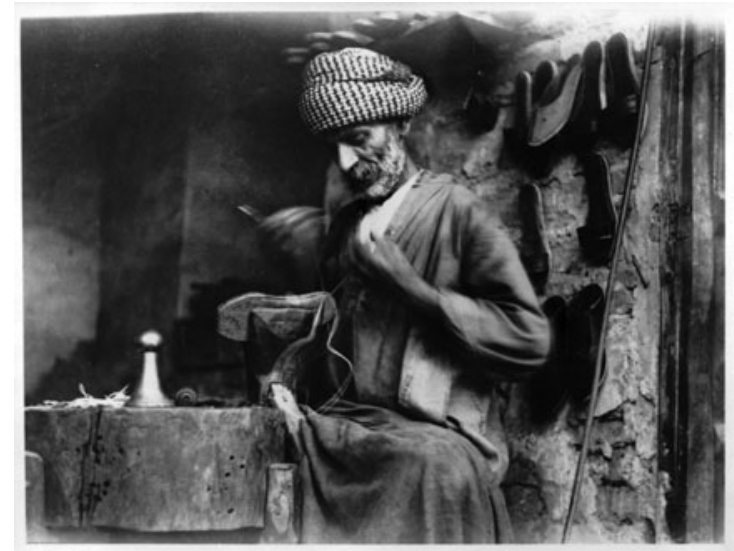

Shoemaker

Baghdad, Iraq, 1928

Kamil Chadirji

Copyright (C) Arab Image Foundation

Rifaat Chadirji, meanwhile, is one of the most prominent architects in the Arab world. Despite living through a turbulent political context - paying the price with an imprisonment of 20 months in Baghdad - he was prolific as an artist and photographer during the second half of the $20^{\text {th }}$ century, both within Iraq and abroad. He is an honorary member of the Royal Institute of British Architects and was previously a Laureate of the Aga Khan Award for Architecture. With regard to his architectural style, R. Chadirji has stated that he 'set out to learn from traditional architecture and to achieve a synthesis between traditional forms and [the] inevitable advent of modern technology' (Morgan and Naylor, 1987). Not unlike his father, 
Rifaat Chadirji sought to document social change in Iraq through his photographs, and has argued that whilst Kamil's photograph bear witness to a slow and peaceful change in Iraqi society, his own images record an 'accelerated, sometimes violent $[\ldots]$ in some aspects very sophisticated and ordered and in most cases chaotic, vulgar and sinister change' (Chadirji, unpublished essay). R. Chadirji's collection at the AIF numbers around 60,000 negatives, featuring his personal photography in addition to photographic documentation of all his architectural projects. Each project - whether completed or merely proposed - was given a unique number, in chronological order. Since arriving at the AIF, these projects have been identified, ordered and documented, ready to be cleaned and processed. The negatives of R. Chadirji's personal photography projects had mostly already been numbered by date and classified by categories that reflect Rifaat's anthropological and sociological approach to photography. The Chadirji collection is today of historical importance and value for researchers and the AIF is actively engaged in fundraising efforts in order to be able to process, document and digitize the collection further. All of these efforts will be conducted under the kind supervision of $\mathrm{Mr}$ Rifaat Chadirji.

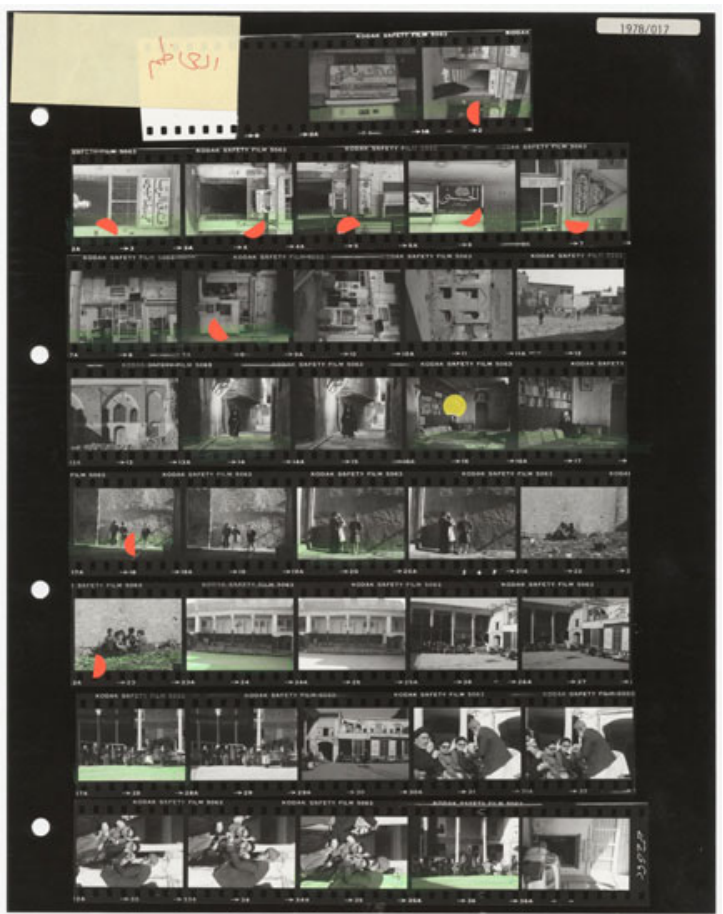

Contact print titled "Al-Azim"

Baghdad, Iraq, 1978

Rifaat Chadirji

Copyright (C) Arab Image Foundation

\section{PRESERVING PHOTOGRAPHS}

The AIF's collection is held in a purpose-built cool storage room located in the foundation's headquarters in Beirut. The facility is an integral part of the foundation's preservation strategy, which adheres to international standards for the conservation of photographic materials. Both climate-controlled and fireproof, the space limits the exposure of photographs to light and variable temperatures. The core staff of the AIF have been trained in working with all of the different photographic materials that are acquired and managed by the foundation. The collection features a broad range of photographic processes, including glass-plate negatives, albumen prints, stereographs, lantern slides, hand-colored prints, gelatin silver prints and negatives on acetate and nitrate film. Prints and negatives are cleaned, numbered, digitized and stored in conditions appropriate to their physical state. The foundation uses a range of housing materials that meet PAT (Photographic Activity Test) standards. Some are imported, while others are specially commissioned from local craftsmen.

In addition to focusing on the preservation of its own archive, the AIF has implemented several successful projects aimed at preserving photographic heritage throughout the Mediterranean and across the Arab world. Its two current preservation projects are the Middle East Photograph Preservation Initiative (MEPPI) and the Modern Heritage Observatory (MoHO). These projects allow the AIF to extend its preservation ambitions and offer its expertise to other regional collections.

\subsection{The Middle East Photograph Preservation Initiative (MEPPI)}

The MEPPI program was initiated jointly by the Arab Image Foundation and two world leaders in photograph conservation, Nora Kennedy and Debra Hess Norris. Kennedy is the Fairchild Conservator of Photographs at the Metropolitan Museum of Art, while Hess Norris chairs the Art Conservation department at the University of Delaware. The ambitious MEPPI program was designed with the goal of identifying, assessing and training significant photograph collections in the Middle East and North Africa upon observing that the conservation and preservation of photography in the region is still in its infancy despite the existence of many invaluable photograph collections. This is partly due to the fact that national libraries and archives, for example, do not uniformly include photographs with their accessioned collections of documents, books, maps, and other materials. Collecting has mostly taken place at colleges, universities, private organizations, ministries of culture, and exists on an individual level. Often, even when these collections exist, they are not always recognized or valued and may not be provided with the staff and funding necessary for their adequate care.

The MEPPI project began in 2009 with a Getty Foundationfunded pilot workshop, during which participants from 10 collections from Egypt, Iran, Jordan and Lebanon were exposed to the fundamental concepts of photograph preservation, followed by concrete applications of theories and techniques. The curriculum included introductions to the technical history of photography, image formation and deterioration, degradation mechanisms and causes. Emphasis was put on hands-on demonstrations and practica. At the conclusion of the workshop, participants developed individual and joint preservation goals, and remained in contact with each other and with their instructors through the platform of the online MEPPI blog.

Following the success of the pilot workshop, the project was renewed with funding from the Andrew W. Mellon Foundation and a partnership with the Getty Conservation Institute. The new MEPPI cycle began in 2011 and is programmed for three years.

The new and improved MEPPI began with a process of identifying significant photograph holdings in the Arab world. Prior to the MEPPI survey, several institutions had endeavored to locate regional collections of all sizes (among others the Institute for Palestine Studies in Ramallah, CULTNAT in Cairo, or the Qatar Unified Imaging Project...) but the collected information is still scattered and not yet readily available to the public and scholars.

Three researchers were selected to conduct the MEPPI survey, and each was assigned a region. Jean-Gabriel Leturcq, a French 
scholar and $\mathrm{PhD}$ researcher, with experience at the Digital Center for the Conservation of Libyan Archives, researched and identified over 120 collections in the Arab Peninsula. Dr Mark Westmoreland, professor of anthropology at the American University of Cairo, identified around 100 collections in Egypt and the Levant - research in Egypt being made possible through collaboration with CULTNAT's program "Photographic Memory of Egypt". Finally, Marie Moignard, independent researcher and curator based in Paris and specializing in the history of Moroccan photography, identified over 50 collections in North Africa. This important research will allow the AIF to build and share a regional directory of photograph collections.

Other research components of MEPPI included the development of an English-Arabic-French glossary of photograph conservation terms that will facilitate the Arabic translation of academic publications on photograph preservation.

During its new cycle, MEPPI also proposes three photograph preservation courses over three years. The first MEPPI course, MEPPI Beirut 2011, was attended by 18 participants from leading photograph collections of the Greater Middle East, including national archives and libraries, museums, press agencies, and universities in Egypt, Iraq, Iran, Jordan, Lebanon, Morocco, Palestine and Syria. ${ }^{*}$ Participants and instructors engaged in theoretical and practical sessions covering the identification, preservation and display of photographic materials, both analog and digital. Participants were provided with preservation toolkits and sample housing materials. Selected participants were also provided with state-of-the-art environment monitoring data-loggers, to gather data on storage conditions. The workshop included collection visits to the American University of Beirut, the Arab Image Foundation, and Studio Shehrazade. A public talk at the Beirut Art Center addressed the critical challenges and best practices associated with digital print preservation.

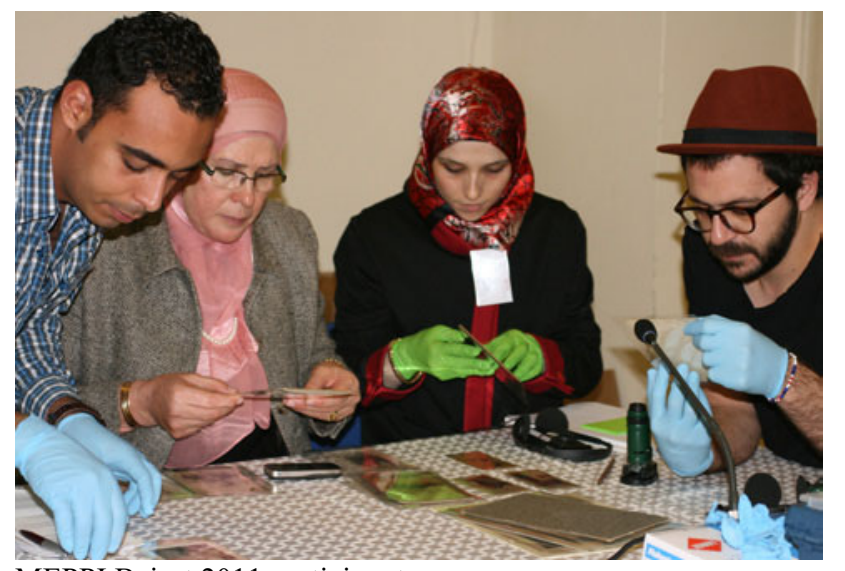

MEPPI Beirut 2011 participants

Tram Vo

Copyright (C) J. Paul Getty Trust

\footnotetext{
* Participating institutions were, from Egypt, the Grand Egyptian Museum and the Qasr el Doubara Institute for Historical Research; from Iran, an independent researcher; from Iraq, the Iraq National Library and Archive and Photographic Memory; from Jordan, the Department of Antiquities, the National Library of Jordan, and the Royal Protocol; from Lebanon, the American University of Beirut, An-nahar, the Arab Image Foundation, the Daralhayat Information Center, and the Fouad Debbas Collection; from Morocco, Bibliothèque Générale et Archives de Tetouan, Bibliothèque Nationale du Royaume du Maroc; from Palestine News and Information Agency, WAFA; from Syria, the City of Aleppo Archive
}

Participants in MEPPI Beirut 2011 have enthusiastically acknowledged the value of the MEPPI courses, both for the skills they gained and the sensitivity they acquired in matters of preservation and shared cultural heritage. Participants were inspired to work together to strengthen the preservation of photographic materials in the Arab world. The 18 participants then engaged in the distance-learning phase of the course, which is coordinated by the Getty Conservation Institute. During this period, assignments ranged from assessing a collection to preparing an emergency plan. Participants disseminated information collected from MEPPI within their institutions and beyond, some even giving public talks on photograph preservation, such as Clare Davies and Ibrahim Abdel-fattah at the Contemporary Image Collective in Cairo, in February 2012. Participants met again as a group in September 2012 to share their accomplishments and to discuss challenges faced. One of the participants had volunteered to host the group for the final meeting, which was held at the National Library of Morocco (Bibliothèque Nationale du Royaume du Maroc). Meanwhile, the selection process is ongoing for the MEPPI Abu Dhabi 2012 course scheduled to run from the 11-19 November 2012 at New York University in Abu Dhabi. The course will provide training to a second group of photograph collections from the Middle East and North Africa A third MEPPI course will take place in the fall of 2013. By the end of the three courses, approximately 50 individuals responsible for photograph collections in Middle East institutions will have received supervised preservation training, and a strong network of like-minded individuals and institutions will have been established.

\subsection{The Modern Heritage Observatory (MoHO)}

The second major preservation project undertaken by the Arab Image Foundation in 2012 is the Modern Heritage Observatory (MoHO), a coalition formed by the AIF and three regional partners: the Arab Center for Architecture (ACA), the Association for Arabic Music (Irab) and the Cinémathèque de Tanger (CDT). The MoHO initiative, funded by the European Commission and in parts by the Heinrich Böll Foundation, aims to advocate for the preservation of modern cultural heritage with an emphasis on photography, music, architecture, video and film - in the Middle East and North Africa. The project's remit was borne out of an absence of sound cultural governance in the Middle East and North Africa, where the preservation of cultural heritage depends almost entirely on the initiative of individuals and a few cultural heritage organizations.

While the partners, and other cultural heritage actors, have managed to gather and preserve important collections that would otherwise have been lost, they struggle for sustainability in a political context characterized by outdated legal frameworks and weak political commitment to cultural heritage. They are determined to mobilise their efforts in order to impact policies. The key constraints addressed by the Modern Heritage Observatory initiative include the lack of systematic coordination and exchange of expertise among cultural heritage actors; the absence of a platform uniting advocacy efforts calling for policy reform and legal protection; the lack of technical and financial support from local actors; and a lack of access to, and participation in, cultural heritage by the general public.

Through the creation of a network for professional bodies from the Middle East and North Africa, the project promotes the exchange of experience, pooling of expertise, and the elaboration of strategies for joint advocacy initiatives. By organizing a variety of activities including trainings, national 
and regional meetings, film screenings, exhibitions and the publishing of articles, the Modern Heritage Observatory will contribute to making modern cultural heritage of the Arab world more extensively preserved and widely accessible.

In March and June 2012, the Arab Image Foundation hosted networking meetings bringing together actors in cultural heritage preservation in Lebanon. Over 30 participants attended the first networking meeting, which served to inaugurate the MoHO initiative. The meeting focused on identifying shared needs and concerns among the actors of cultural heritage in Lebanon, and aimed at building the basis of the network and discussing common goals and objectives. Building on the concerns identified, participants were then asked to fill in a survey assessing their needs and detailing their expectations from the network. Accordingly, the second networking meeting addressed two critical topics that had emerged from participants' answers: emergency preparedness, and the need for a common visibility and communication strategy. As emergency plans are a key tool for archive repositories, network members decided on creating working groups, where those holding comparably-sized archives of similar media will together develop emergency salvage plans.

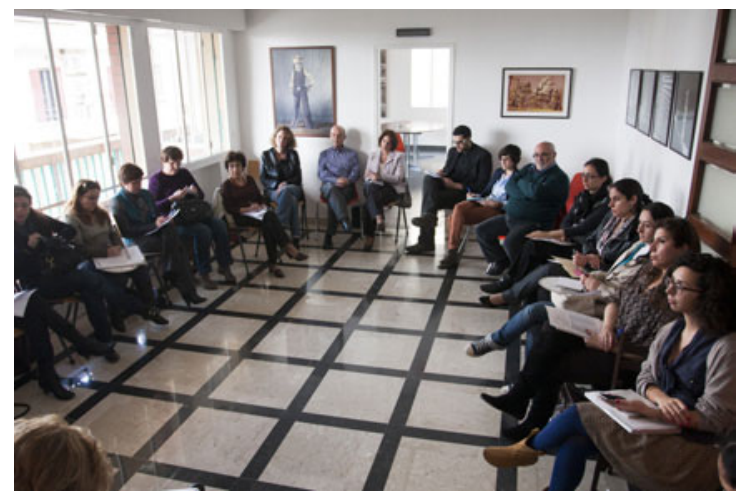

MoHO national networking meeting \#1

Beirut, March 2012

Walid Sader

Copyright $(\mathbb{C}$ Arab Image Foundation

In addition, an online platform is being launched by the AIF and its MoHO partners that will facilitate the network members' discussion and provide a space to share their opinions and concerns with regard to emergency procedures and other cultural heritage issues. The platform, to be launched in the fall of 2012, will be a reference point for cultural heritage information and news from the Middle East and North Africa. During 2012-3, four other national networking meetings will be hosted by the AIF, each focusing on a specific theme or issue voted on by the MoHO network members, such as lobbying strategies, policy propositions, and trainings. Similarly, the Cinémathèque de Tanger will host two networking meetings in Morocco, with similar goals and methods. Additionally, two regional networking meetings will be organized by the Heinrich Böll Foundation, allowing for the discussion to be opened up to regional actors of cultural heritage preservation.

To ensure the sustainability of the project's impact, MoHO also includes a strong educational component. Through the Modern Heritage Observatory, the AIF was able to send an archivist to be trained at the Musée Nicéphore Niépce in France, and to gain skills and knowledge in archiving and preservation. Staff members of other partners in MoHO are also benefiting from technical training in the physical and digital preservation of their archives. In return, the AIF is offers free training in the digitization of photography to a number of institutions requiring such technical skills. To date, these services have allowed several collections representatives in Lebanon, Palestine and Iran to receive one-on-one technical training in digitization.

Future project activities will include collective lobbying for better regional policies. In particular, 2013 will witness the publication of policy briefing papers by Modern Heritage Observatory members, which will discuss recommendations for policy reform and practices related to the preservation and protection of cultural heritage.

\section{CONCLUSION}

The development of new preservation and educational activities at the Arab Image Foundation in recent years has established a blueprint for the large community of individuals and institutions committed to the preservation of photographic heritage.

Remaining challenges for the preservation of photographic heritage in the Arab world are two-fold. Firstly, to campaign for the commitment of local and regional agencies to draw up strong policies for the protection of modern cultural heritage; secondly, to secure local and regional funding for preservation projects that are, currently, for the most part, funded externally.

\section{REFERENCES AND SELECTED BIBLIOGRAPHY}

Arab Image Foundation, 2004. Hashem el Madani: Promenades, Mind the Gap (ed.)

Arab Image Foundation, 2004. Hashem el Madani: Studio Practices, Mind the Gap

Chadirji, R. Social Change in Iraq, unpublished essay

Kennedy, N. (et al.), 2010. Preservation of the photographic heritage of the Eastern Mediterranean, presented at the 2010 IIC congress in Istanbul

Morgan, A. and Naylor, C., 1987. Contemporary Architects, St. James Press, Chicago, p. 163

\section{ACKNOWLEDGMENTS:}

The Middle East Photograph Preservation Initiative is funded by the Andrew W. Mellon Foundation and the Getty Conservation Institute, and coordinated by the Arab Image Foundation in Beirut, along with the University of Delaware and the Metropolitan Museum of Art.

The Modern Heritage Observatory initiative is funded by the European Commission (project number DCI-HUM/2011/272036), coordinated by the Heinrich Böll Foundation in Beirut, and led jointly with the Arab Center for Architecture (ACA), the Association for Arabic Music (Irab) and the Cinémathèque de Tanger.

The authors would like to thank Nora Kennedy and Debbie Hess Norris for providing inspiration and guidance, and Sarah Morris for her skillful editing. 
